\title{
PERFORMANCE-BASED PLASTIC DESIGN AND ENERGY-BASED EVALUATION OF SEISMIC RESISTANT RC MOMENT FRAME
}

\author{
Wen-Cheng Liao \\ Department of Civil Engineering, National Taiwan University, Taipei, Taiwan., wcliao@ntu.edu.tw \\ Subhash C. Goel \\ Department of Civil and Environmental Engineering, University of Michigan, Ann Arbor, Michigan, U.S.A.
}

Follow this and additional works at: https://jmstt.ntou.edu.tw/journal

Part of the Civil and Environmental Engineering Commons

\section{Recommended Citation}

Liao, Wen-Cheng and Goel, Subhash C. (2012) "PERFORMANCE-BASED PLASTIC DESIGN AND ENERGY-BASED

EVALUATION OF SEISMIC RESISTANT RC MOMENT FRAME," Journal of Marine Science and Technology: Vol. 20: Iss.

3, Article 9.

DOI: $10.51400 / 2709-6998.1808$

Available at: https://jmstt.ntou.edu.tw/journal/vol20/iss3/9

This Research Article is brought to you for free and open access by Journal of Marine Science and Technology. It has been accepted for inclusion in Journal of Marine Science and Technology by an authorized editor of Journal of Marine Science and Technology. 


\title{
PERFORMANCE-BASED PLASTIC DESIGN AND ENERGY-BASED EVALUATION OF SEISMIC RESISTANT RC MOMENT FRAME
}

\author{
Wen-Cheng Liao ${ }^{1}$ and Subhash C. Goel ${ }^{2}$
}

\begin{abstract}
Key words: performance-based plastic design, reinforced concrete moment frames, earthquake resistant design, seismic demand evaluation.
\end{abstract}

\begin{abstract}
This paper presents first time application of the Performance-Based Plastic Design (PBPD) approach to seismic resistant reinforced concrete special moment frames (RC SMF). Four baseline RC SMF (4, 8, 12 and 20-story) as used in the FEMA P695 were selected for this study. Those frames were redesigned by the PBPD approach. The baseline code designed frames and the PBPD frames were subjected to extensive inelastic pushover and time-history analyses. It turns out that the work-energy equation in PBPD to determine design base shear can also be used to estimate seismic demands, herein called the energy spectrum method. In summary, this study shows that the PBPD approach can be successfully applied for seismic design of RC structures as well. The seismic responses of the study frames met the targeted performance criteria with dramatic improvement over the corresponding baseline code designed frames. In addition, the drift demands of all study frames as computed by the energy spectrum method were in excellent agreement with those obtained from detailed inelastic dynamic analyses.
\end{abstract}

\section{INTRODUCTION}

Reinforced concrete special moment frames (RC SMF) comprise of horizontal framing components (beams and slabs), vertical framing components (columns) and joints connecting horizontal and vertical framing components that are designed to meet the special requirements given in seismic codes $[1,2]$. In seismic provisions, certain requirements such as special proportioning and detailing requirements result in a frame capable of resisting strong earthquake shaking without sig-

Paper submitted 03/25/11; revised 12/13/11; accepted 04/11/12. Author for correspondence: Wen-Cheng Liao (e-mail: wcliao@ntu.edu.tw).

${ }^{I}$ Department of Civil Engineering, National Taiwan University, Taipei, Taiwan.

${ }^{2}$ Department of Civil and Environmental Engineering, University of Michigan, Ann Arbor, Michigan, U.S.A. nificant loss of strength. Nevertheless, structural and nonstructural damage observed in code compliant RC buildings due to undesired failure modes [12] have shown the need to develop alternative methodologies to better ensure the desired performance. Since RC SMF has been widely used as part of seismic force-resisting systems, design methodologies and systematic procedures are needed which require no or little iteration after initial design in order to meet the targeted design objectives.

Performance-Based Plastic Design (PBPD) method has been recently developed to achieve enhanced performance of earthquake resistant steel structures. This paper presents first time application of the PBPD approach to seismic resistant RC SMF [11]. RC structures present special challenge because of their complex and degrading ("pinched") hysteretic behavior. In order to account for the degrading hysteretic behavior the FEMA $440 C_{2}$ factor concept [7] was used in developing the process of determining the design base shear for targeted drift and yield mechanism in the PBPD methodology. Four baseline RC SMF (4, 8, 12 and 20-story) as used in the FEMA P695 [6] were selected for this study. Those frames were redesigned by the PBPD approach. The baseline code designed frames and the PBPD frames were subjected to extensive inelastic pushover and time-history analyses.

It turns out that the work-energy equation to determine design base shear can also be used to estimate seismic demands, herein called the energy spectrum method. In this approach the skeleton force-displacement (capacity) curve of the structure is converted into energy capacity-displacement plot $\left(E_{c}\right)$ which is superimposed over the corresponding energy demand plot $\left(E_{d}\right)$ for the specified hazard level to determine the expected peak displacement demands

\section{PERFORMANCE-BASED PLASTIC DESIGN (PBPD) METHOD}

\section{Background}

Performance-Based Plastic Design (PBPD) method, which accounts for inelastic structural behavior directly, and practically requires no or little iteration after initial design, has been developed by Goel et al. [8]. By using the concept of energy balance applied to a pre-selected yield mechanism with proper 


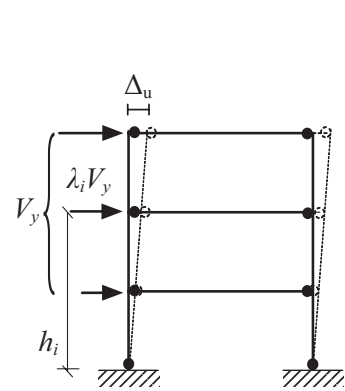

(a)

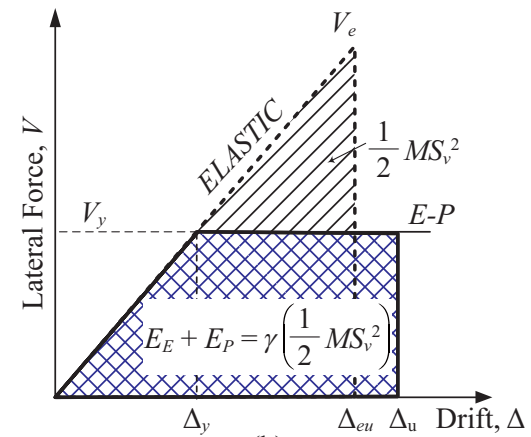

(b)
Fig. 1. The energy equating concept for deriving design base shear of PBPD method.

strength and ductility, structures designed by the PBPD method can achieve more predictable structural performance under strong earthquake ground motions. It is important to select a desirable yield mechanism and target drift as key performance limit states for given hazard levels right from the beginning of the design process. The distribution and degree of structural damage are greatly dependent on these two limit states. In addition, the design base shear for a given hazard level is derived corresponding to a target drift limit of the selected yield mechanism by using the input energy from the design pseudo-velocity spectrum: that is, by equating the work needed to push the structure monotonically up to the target drift (Fig. 1(a)) to the energy required by an equivalent elastic-plastic single-degree-of-freedom (EP-SDOF) system to achieve the same state (Fig. 1(b)). Furthermore, a better representative distribution of lateral design forces is also used in this study, which is based on inelastic dynamic response results [3]. This lateral design force distribution accounts for higher mode effects and inelastic behavior better than the distribution prescribed by the current codes.

Mechanism based plastic analysis is used to determine the required of the designated yielding frame members, such as beams in RC SMF, to achieve the selected yield mechanism. Design of non-yielding members, such as columns, is then performed by considering the equilibrium of an entire "column tree" in the ultimate limit state to ensure formation of the selected yield mechanism. It is also worth mentioning that the PBPD method has been successfully applied to steel moment frames, concentrically braced frames, buckling restrained braced frames, eccentrically braced frames and special truss moment frames. The theoretical background and detailed design procedures of the PBPD method can be found in several publications [8].

\section{Determination of Design Base Shear}

Determination of the design base shear for a given hazard level is a key element in the PBPD method. It is calculated by equating the work needed to push the structure monotonically up to the target drift to that required by an equivalent elastic-plastic single degree of freedom (EP-SDOF) system to

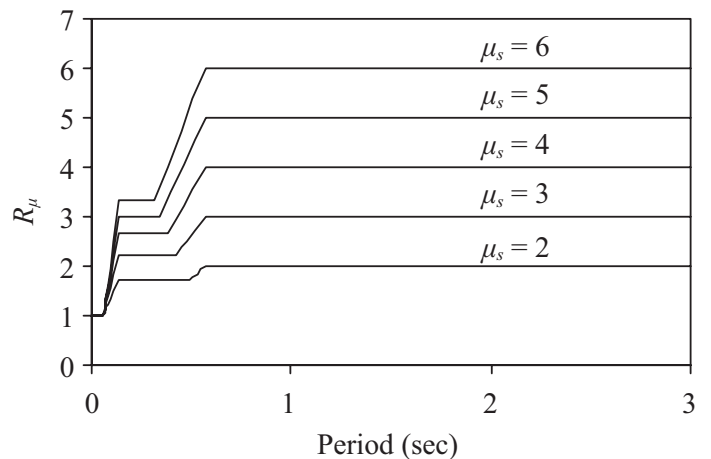

Fig. 2. Idealized inelastic spectra by Newmark and Hall for EP-SDOF (1982).

achieve the same state. Assuming an idealized E-P forcedeformation behavior of the system (Fig. 1), the work-energy equation can be written as:

$$
\left(E_{e}+E_{p}\right)=\gamma \cdot\left(\frac{1}{2} M \cdot S_{v}{ }^{2}\right)=\frac{1}{2} \gamma \cdot M \cdot\left(\frac{T}{2 \pi} S_{a} \cdot g\right)^{2}
$$

where $E_{e}$ and $E_{p}$ are, respectively, the elastic and plastic components of the energy (work) needed to push the structure up to the target drift. $S_{v}$ is the design pseudo-spectral velocity; $S_{a}$ is the pseudo spectral acceleration; $T$ is the natural period; and $M$ is the total mass of the system. Using the geometric relationship between the two areas representing work and energy in Fig. 1(b), Eq. (1) can be written as:

$$
\frac{1}{2} \cdot V_{y} \cdot\left(2 \Delta_{u}-\Delta_{y}\right)=\gamma \cdot\left(\frac{1}{2} \cdot V_{e} \cdot \Delta_{e u}\right)
$$

Eq. (2) can be further reduced into the following form:

$$
\gamma \frac{\Delta_{e u}}{\Delta_{y}}=\frac{\left(2 \Delta_{u}-\Delta_{y}\right)}{\Delta_{e u}}
$$

The energy modification factor, $\gamma$, depends on the structural ductility factor $\left(\mu_{s}\right)$ and the ductility reduction factor $\left(R_{\mu}\right)$, and can be obtained by the following relationship:

$$
\gamma=\frac{2 \mu_{s}-1}{R_{\mu}^{2}}
$$

Because of its simplicity, spectra proposed by Newmark and Hall [13] as shown in Fig. 2 were used to relate $R_{\mu}$ and $\mu_{s}$, for EP-SDOF. Plots of energy modification factor $\gamma$ as obtained from Eq. (4) are shown in Fig. 3.

The work-energy equation can be re-written in the following form: 


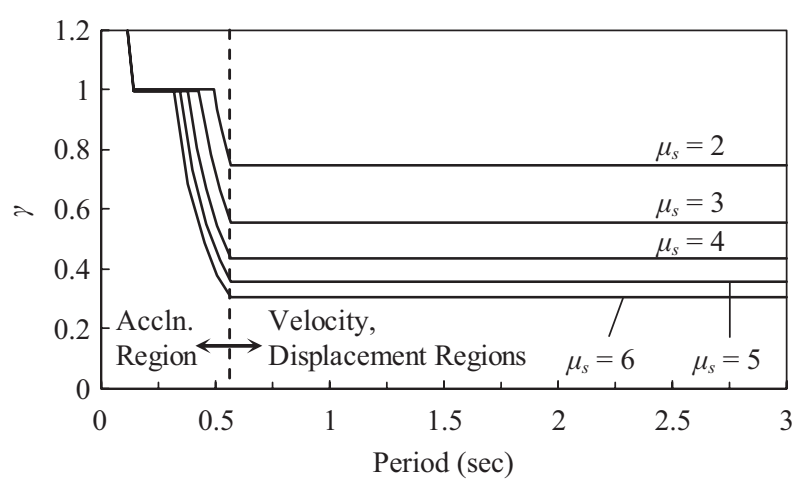

Fig. 3. Energy modification factor, $\gamma$, versus period.

$$
\frac{1}{2}\left(\frac{W}{g}\right) \cdot\left(\frac{T}{2 \pi} \frac{V_{y}}{W} g\right)^{2}+V_{y}\left(\sum_{i=1}^{N} \lambda_{i} h_{i}\right) \theta_{p}=\frac{1}{2} \gamma\left(\frac{W}{g}\right) \cdot\left(\frac{T}{2 \pi} S_{a} g\right)^{2}
$$

or

$$
\left(\frac{V_{y}}{W}\right)^{2}+\frac{V_{y}}{W}\left(h^{*} \cdot \frac{\theta_{p} 8 \pi^{2}}{T^{2} g}\right) \theta_{p}-\gamma S_{a}^{2}=0
$$

where $V_{y}, \lambda_{i}$ and $\theta_{p}$ present the yielding base shear (can be also used as the design base shear), shear distribution factor for each floor $\mathrm{i}$, and the global inelastic drift ratio of the structure, respectively. The admissible solution of Eq. (6) gives the required design base shear coefficient, $V_{y} / W$ :

$$
\frac{V_{y}}{W}=\frac{-\alpha+\sqrt{\alpha^{2}+4 \gamma S_{a}^{2}}}{2}
$$

where $\alpha$ is a dimensionless parameter given by

$$
\alpha=\left(h^{*} \cdot \frac{\theta_{p} 8 \pi^{2}}{T^{2} g}\right)
$$

and

$$
h^{*}=\sum_{i=1}^{N}\left(\lambda_{i} h_{i}\right)
$$

\section{SPECIAL CONSIDERATIONS FOR RC SMF IN PBPD METHOD}

RC structures present special challenge due to their complex and degrading (pinched) hysteretic behavior. While development of the PBPD method for RC structures is currently in progress, results from the study so far have been most promising.

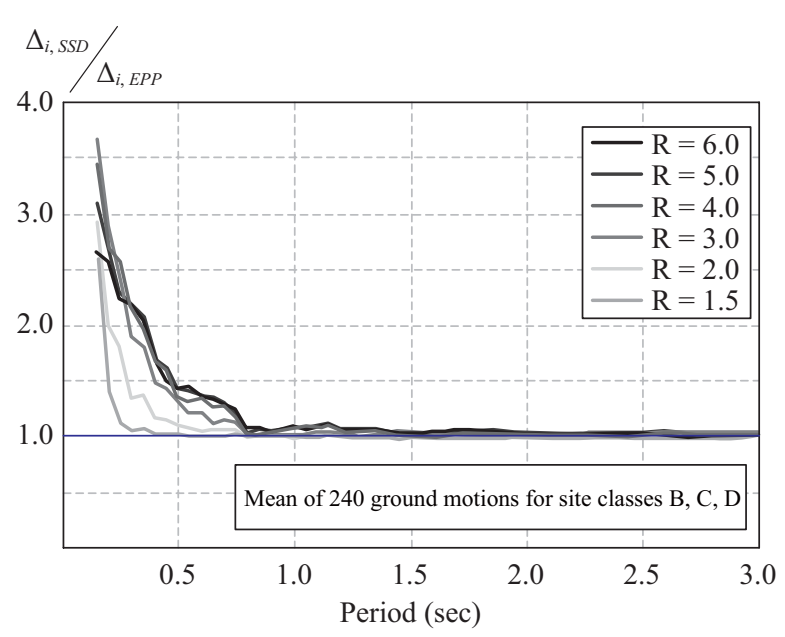

Fig. 4. Mean displacement ratio of SSD to EPP models $\left(C_{2}\right)$ computed with ground motions recorded on site classes $B, C$, and D [7].

The design base shear was determined for two level performance criteria: (1) a $2 \%$ maximum story drift ratio $\left(\theta_{u}\right)$ for a ground motion hazard with a $10 \%$ probability of exceedance in 50 years (10/50 and 2/3 MCE), and (2) a $3 \%$ maximum story drift ratio $\left(\theta_{u}\right)$ for a $2 / 50$ event (maximum credible earthquake, MCE). Design of RC SMF with PBPD method basically follows the same procedure as that of steel frames with the following two modifications for determination of design base shear to account for pinched hysteretic behavior and P-Delta effect.

\section{Pinched Hysteretic Behavior}

Investigators have studied the effect of degrading hysteretic behavior of SDOF systems on resulting peak displacements. The results show that the peak displacements are larger than those of systems with non-degrading hysteretic behavior in the short period range, but are about equal for longer periods. Approximate expressions have been proposed for modification factors to account for this effect, e.g., $C_{2}$ factor in FEMA 440 [7], Fig. 4. $C_{2}$ factor is the modification factor to represent the effects of pinched hysteresis shape, stiffness deterioration and strength deterioration on maximum displacement response. Thus, the target design drift for a given structural system with degrading hysteretic behavior can be divided by the $C_{2}$ factor that would give design target drift for an equivalent non-degrading system. The design base shear can then be calculated by using this modified target drift.

\section{P-Delta Consideration}

Due to stiffness and strength degradation at beam plastic hinges it was found necessary to include P-Delta effect in the determination of required moment capacity of beams for the RC SMF. That was accomplished by adding "P-Delta lateral force", $F_{i-P D}$, to the basic design force, $F_{i}$. The force $F_{i-P D}$ can be taken equal to $P_{i} \theta_{u}$, where $P_{i}$ represents the tributary gravity load at floor level $i$ and $\theta_{u}$ the target design drift ratio which 
Table 1. Design parameters for PBPD RC SMF.

\begin{tabular}{|c|c|c|c|c|c|c|c|c|}
\hline \multirow{2}{*}{$\begin{array}{c}\text { Design } \\
\text { Parameters }\end{array}$} & \multicolumn{2}{|c|}{ 4-story } & \multicolumn{2}{c|}{8 -story } & \multicolumn{2}{c|}{12 -story } & \multicolumn{2}{c|}{20 -story } \\
\cline { 2 - 9 } & $2 / 3 \mathrm{MCE}$ & $\mathrm{MCE}$ & $2 / 3 \mathrm{MCE}$ & $\mathrm{MCE}$ & $2 / 3 \mathrm{MCE}$ & $\mathrm{MCE}$ & $2 / 3 \mathrm{MCE}$ & $\mathrm{MCE}$ \\
\hline $\mathrm{Sa}$ & $0.74 \mathrm{~g}$ & $1.11 \mathrm{~g}$ & $0.40 \mathrm{~g}$ & $0.60 \mathrm{~g}$ & $0.30 \mathrm{~g}$ & $0.45 \mathrm{~g}$ & $0.30 \mathrm{~g}$ & $0.45 \mathrm{~g}$ \\
\hline $\mathrm{T}(\mathrm{sec}$ ) & 0.81 & 0.81 & 1.49 & 1.49 & 2.13 & 2.13 & 3.36 & 3.36 \\
\hline$C_{2}$ & 1.1 & 1.1 & 1.07 & 1.07 & 1.04 & 1.04 & 1 & 1 \\
\hline Yield Drift & $0.5 \%$ & $0.5 \%$ & $0.5 \%$ & $0.5 \%$ & $0.5 \%$ & $0.5 \%$ & $0.5 \%$ & $0.5 \%$ \\
\hline Target Drift & $2 \%$ & $3 \%$ & $2 \%$ & $3 \%$ & $2 \%$ & $3 \%$ & $2 \%$ & $3 \%$ \\
\hline $\begin{array}{c}\text { Modified Target } \\
\text { Drift }\end{array}$ & $1.82 \%$ & $2.73 \%$ & $1.87 \%$ & $2.81 \%$ & $1.92 \%$ & $2.89 \%$ & $2 \%$ & $3 \%$ \\
\hline$\mu$ & 3.64 & 5.46 & 3.74 & 5.61 & 3.85 & 5.77 & 4 & 6 \\
\hline$R_{\mu}$ & 3.64 & 5.46 & 3.74 & 5.61 & 3.85 & 5.77 & 4 & 6 \\
\hline$\gamma$ & 0.47 & 0.33 & 0.46 & 0.32 & 0.45 & 0.32 & 0.44 & 0.31 \\
\hline$\alpha$ & 2.103 & 3.552 & 1.243 & 2.092 & 0.937 & 1.570 & 0.662 & 1.103 \\
\hline$V / W$ & 0.117 & 0.112 & 0.0577 & 0.0552 & 0.0416 & 0.0398 & 0.055 & 0.054 \\
\hline$V$ w/o $P D$ (kips) & 242.2 & 231.8 & 107.1 & 102.5 & 116.3 & 111.3 & 255.0 & 248.0 \\
\hline$\Sigma F_{i-P D}$ (kips) & 41.5 & 62.2 & 36.9 & 55.3 & 55.9 & 83.7 & 92.0 & 138.0 \\
\hline $\begin{array}{c}\text { Design Base } \\
\text { Shear w/ P-D }\end{array}$ & 283.7 & 294.0 & 144.0 & 157.8 & 172.2 & 195.0 & 347.0 & 386.0 \\
\hline
\end{tabular}

is assumed constant over height of the structure for simplicity of design purposes. The values of $F_{i-P D}$ and all design parameters for the PBPD frames are shown in Table 1. Their influence on the total lateral design force can be clearly noticed as it has significant effect on the required frame strength.

\section{REDESIGN OF RC SMF IN FEMA P695 BY PBPD METHOD}

Four examples of 4, 8, 12 and 20-story RC special moment frame structures are briefly presented in this section. All of them were space frames. The baseline space frames were designed to comply with the requirements of ASCE 7-05 and ACI 318-05 in FEMA P695 by Haselton [9]. The frames were then redesigned by the modified PBPD method by using the FEMA $440 C_{2}$ factor approach and considering P-Delta effect as discussed earlier. Typical floor plan is shown in Fig. 5, and important design parameters are given in Table 1. For response evaluation purposes the baseline code compliant frames and the PBPD frames were subjected to inelastic pushover and time-history analyses.

\section{COMPARISON OF PERFORMANCES OF THE BASELINE AND PBPD SMF}

Nonlinear static (pushover) and dynamic (time-history) analyses were carried out for the baseline and PBPD frames by using Perform-3D program [4]. A lumped "P-Delta column" with pin connections at the floor levels was added which enables the model to capture the P-Delta effect. Stiffness, strength and cyclic degradation of moment-rotation behavior of plastic hinges were also modeled to account for the pinched hysteretic behavior.

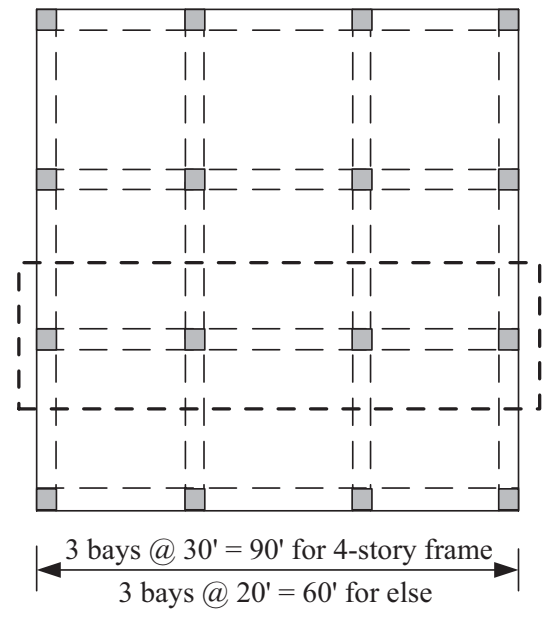

Fig. 5. Floor plan of RC space moment frame building.

The pushover curves for the eight frames in Fig. 6 show that, even though the design base shear for the baseline frame is smaller than that of the corresponding PBPD frame, the ultimate strength of the baseline frame is higher than that of the corresponding PBPD frame. That is mainly due to the fact that the design of the baseline frame was governed by drift which required major revision of the member sizes after having been designed for strength. That iteration step is not needed in the PBPD method. Calculated values of $R_{\max }$ for the baseline and PBPD frames according to the recommended equation in FEMA P440A [5] are 12.5/15.4, 5.0/17.5, 3.2/14.6 and 5.3/10.8, for the $4,8,12,20$-story frames respectively. That reflects much enhanced margin against dynamic instability (collapse) of the PBPD frame over that of the baseline frames.

Fig. 7 shows comparison of maximum interstory drifts of 

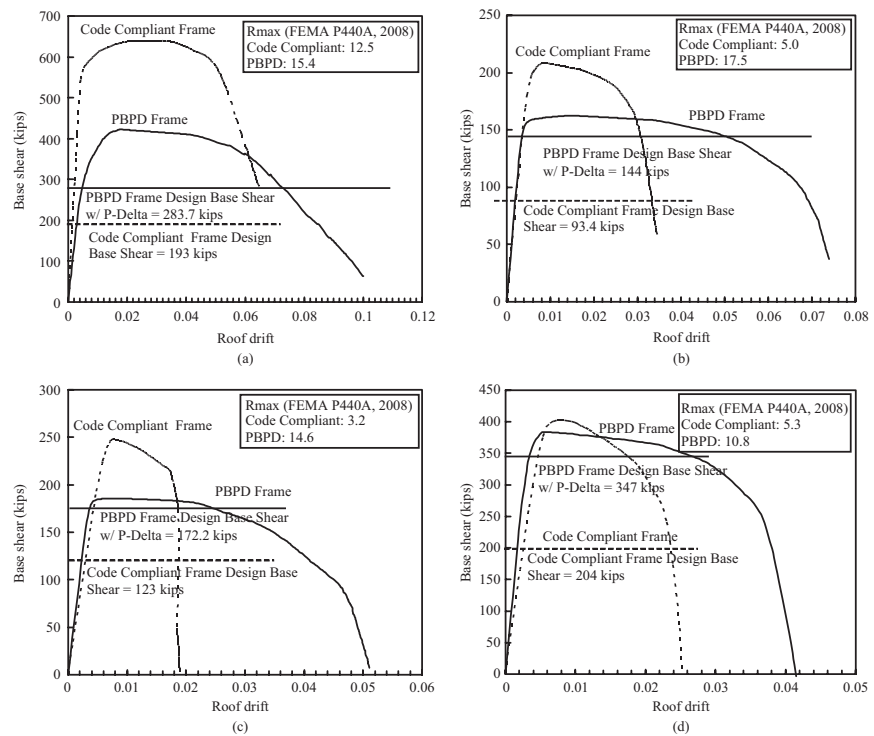

Fig. 6. Pushover curves for (a) 4-story, (b) 8-story, (c) 12-story and (d) 20-story baseline and PBPD frames.
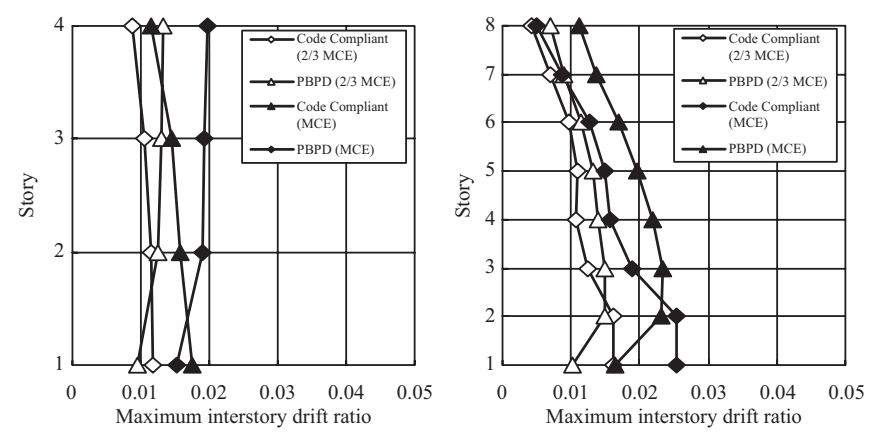

(a)

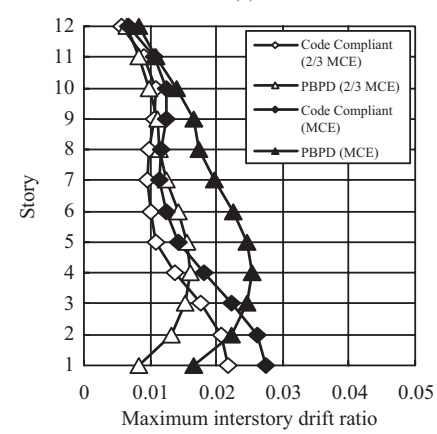

(c)

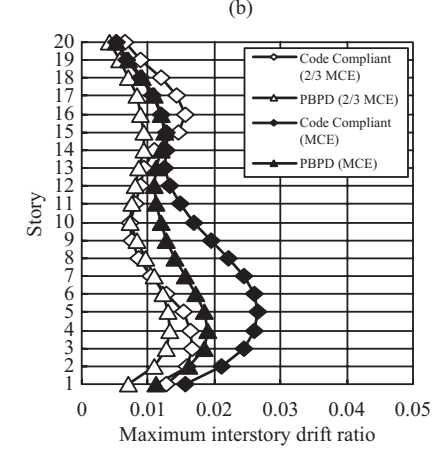

(d)
Fig. 7. Comparison of maximum interstory drifts by time-history analyses of code complaint and PBPD frames for 2/3 MCE and MCE hazard levels (a) 4-story, (b) 8-story, (c) 12-story, and (d) 20-story.

the baseline and PBPD frames obtained from time-history analyses using appropriately scaled ground motion records representative of 2/3 MCE and MCE hazard levels. For clarity and brevity only the mean values of maximum interstory drifts are shown here. The results show that the mean maximum interstory drifts of the PBPD frames are well within the corresponding target values, i.e., $2 \%$ for $2 / 3 \mathrm{MCE}$ and $3 \%$ for

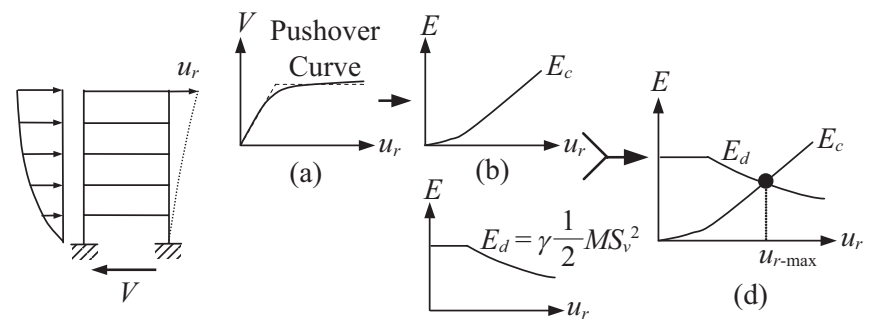

(c)

Fig. 8. Proposed energy-based evaluation method for MDOF systems: (a) Push-over curve, (b) Energy-displacement capacity diagram, (c) Energy demand diagram, and (d) Determination of displacement demand.

MCE. Moreover, the story drifts of the PBPD frames are more evenly distributed over the height as compared with those of the baseline frame where undesirable "softness" in the lower stories is evident, which is caused mainly by plastic hinges in the columns. Formation of plastic hinges in the columns and story mechanism in the lower part of the baseline frames can be clearly noticed. In contrast, there are no unintended plastic hinges in the columns of the PBPD frame, resulting in more favorable deformed shape and yield pattern as intended in the design process.

\section{ENERGY-BASED EVALUATION}

\section{Energy Balance Concept}

In the previous section the energy-based PBPD method was presented and discussed in the context of design of new structures for a target maximum drift. Therefore, with other terms being known, the design base shear is determined by solving the work-energy Eq. (1). It turns out that the same energy equation can also be used for evaluation purposes, where the structure is defined, including its force-displacement characteristics, and the goal is to "predict" the expected maximum displacements for a given seismic hazard [10]. Other response quantities, such as component forces and deformation demands, can then be easily calculated from the maximum reference displacement.

Fig. 8 presents a graphical illustration of the evaluation process. Lateral force-displacement plot for the given structure is shown in Fig. 8(a), where $V$ represents the total force (base shear), and $u_{r}$ the roof displacement, used as reference displacement. This plot can be obtained by a static pushover analysis by applying either an appropriately selected force or displacement pattern. It is common to plot total force versus roof displacement, but it can be done for any other floor or story level from which the force or displacement at other levels can be determined. The energy capacity curve, $E_{c}-u_{r}$, can be generated as a function of $u_{r}$, by calculating the work done by lateral forces up to the displacement at each level corresponding to $u_{r}$, Fig. 8(b). Next, the energy demand, $E_{d}$, can be calculated for varying values of $u_{r}$, and plotted as shown in 


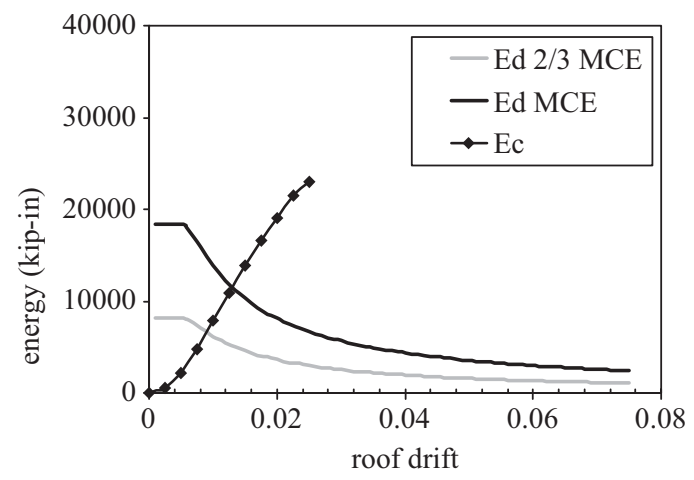

(a)

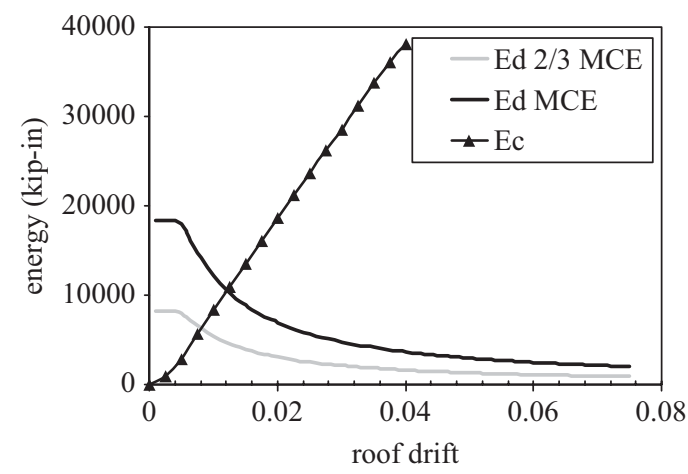

(b)

Fig. 9. Energy spectrum evaluation methods for 20-story RC (a) Baseline and (b) PBPD frame.

Fig. 8(c). The point of intersection of the two curves, where the energy demand and capacity become equal, gives the desired maximum roof displacement, as shown in Fig. 8(d).

\section{Example: 20-Story RC SMF}

Two 20-story frames are briefly presented in this section. One is the baseline space frame from FEMA P695 Project which was designed to comply with current building code provisions. The other frame was redesigned by the PBPD method. In terms of energy spectrum method for evaluation purpose, the energy capacity and demand curves of these two frames are shown in Fig. 9. For each frame, the capacity curve was obtained by calculating the work done by the applied forces in the pushover analysis. The energy capacity corresponding to each roof drift was calculated by numerically integrating the lateral load-deflection values at the floor levels. The energy demand curve was obtained by using the total mass of the frame. The peak roof drift demand was determined from the intersection point of the corresponding demand and capacity curves.

Fig. 10 shows comparison of maximum interstory drifts of the two frames as calculated by the energy spectrum method with those obtained from the time-history analyses using appropriately scaled ground motion records representative of 2/3 MCE hazard levels. It is worth noting that the interstory drifts predicted by the energy spectrum method are in excel-

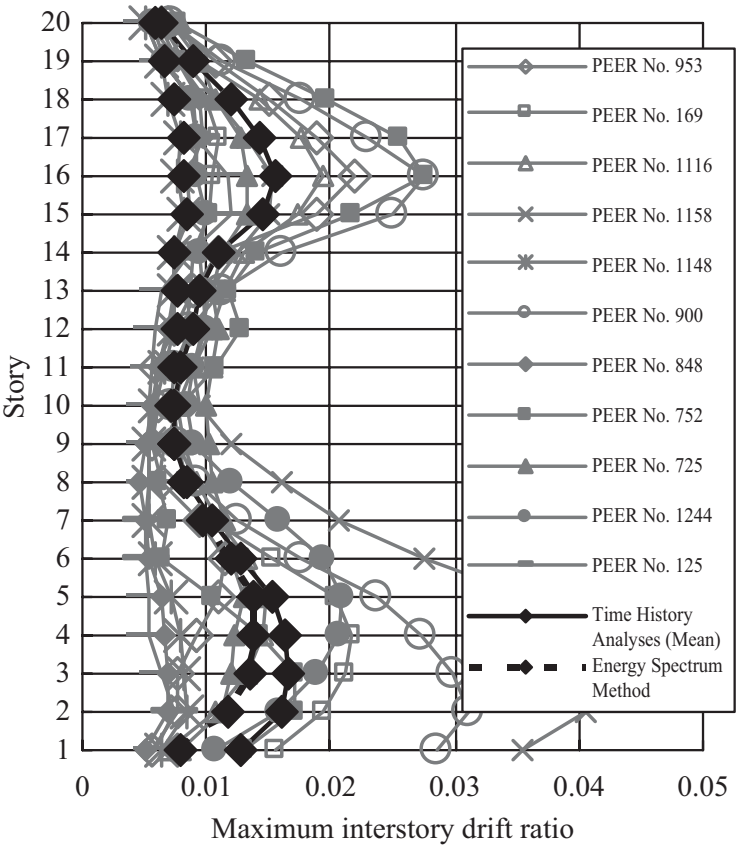

(a)

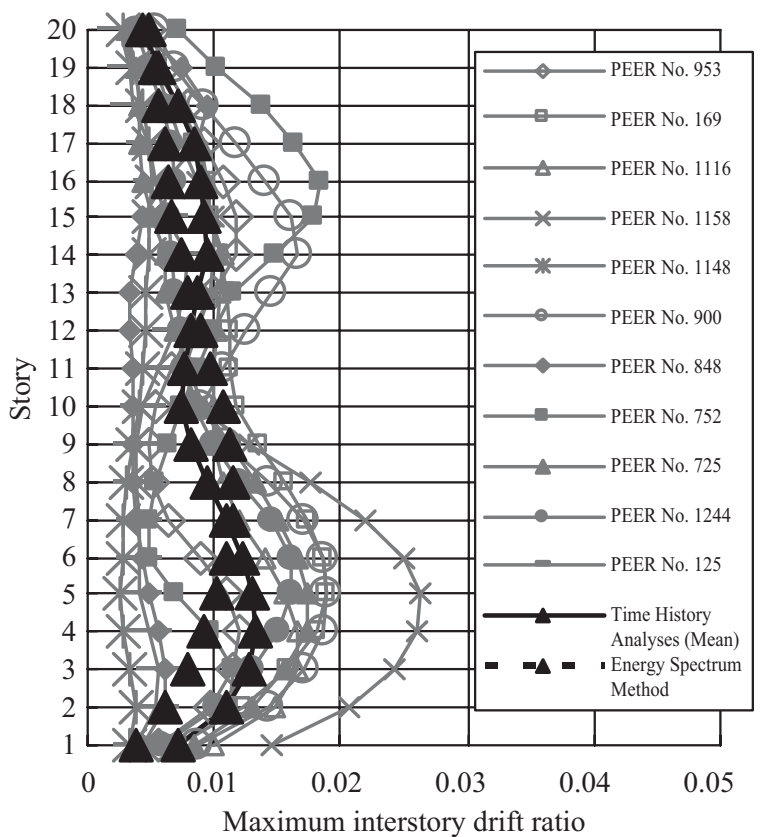

(b)

Fig. 10. Comparison of maximum interstory drifts by the energy spectrum method and time-history analyses under 2/3 MCE for 20-story RC (a) baseline frame and (b) PBPD frame.

lent agreement with those obtained from the dynamic analyses for both frames, but more so for the PBPD frame.

\section{CONCLUSION}

The PBPD method is a direct design method which uses pre-selected target drift and yield mechanism as key performance objectives, which determine the degree and distri- 
bution of expected structural damage. By modifying the determination of design base shear due to pinched hysteretic behavior and P-Delta effect, the PBPD method was successfully applied to the design of RC moment frames. The 4, 8, 12 and 20-story baseline frames used in FEMA P695 Project were redesigned by the modified PBPD method. The PBPD frames responded as intended in design with dramatic improvement in their performances over those of the corresponding baseline frames. In addition, the basic work-energy equation can also be used for seismic evaluation purposes where the goal is to determine expected displacement demand for a given structure and earthquake hazard. The results as presented in this paper showed excellent agreement with those obtained from more elaborate inelastic time-history analyses.

\section{REFERENCES}

1. ACI Committee 318, "Building code requirements for reinforced concrete and commentary (ACI318-08/ACI318R-08)," American Concrete Institute, Detroit (2008).

2. ASCE 7-05, "Minimum design loads for buildings and other structures," American Society of Civil Engineers, Reston, Virginia (2005).

3. Chao, S.-H., Goel, S. C., and Lee, S.-S., "A seismic design lateral force distribution based on inelastic state of structures," Earthquake Spectra, Earthquake Engineering Research Institute, Vol. 23, No. 3, pp. 547-569 (2007).

4. Computers \& Structures Inc., "PERFORM-3D v.4.0 user manual," CSI,
Berkeley, CA (2007).

5. FEMA P440A, "Effects of strength and stiffness degradation on seismic response (ATC-62 Project)," Federal Emergency Management Agency, Washington, D.C. (2009)

6. FEMA P695, "Quantification of building seismic performance factors (ATC-63 Project)," Federal Emergency Management Agency, Washington, D.C. (2009).

7. FEMA 440, "Improvement of nonlinear static seismic analysis procedures," Federal Emergency Management Agency, Washington, D.C. (2006).

8. Goel, S. C. and Chao, S.-H., Performance-Based Plastic Design: Earthquake-Resistant Steel Structures, ICC, USA (2009).

9. Haselton, C. B. and Deierlein, G. G., "Assessing seismic collapse safety of modern reinforced concrete moment frame buildings," Report No. 156, The John, A. Blume Earthquake Engineering Center, Department of Civil and Environmental Engineering, Stanford University (2007).

10. Leelataviwat, S., Saewon, W., and Goel, S. C., "An energy based method for seismic evaluation of structures," Proceedings of Structural Engineers Association of California Convention SEAOC, Lake Tahoe, California, pp. 21-31 (2007).

11. Liao, W.-C. and Goel, S. C., "Performance-based plastic design of earthquake resistant reinforced concrete moment frames," Technical Report No. UMCEE 10-01, University of Michigan, Ann Arbor, MI (2010)

12. Moehle, J. P. and Mahin, S. A., "Observations on the behavior of reinforced concrete buildings during earthquakes," in: Ghosh, S. K. (Ed.), Earthquake-Resistant Concrete Structures - Inelastic Response and Design, ACI SP-127, American Concrete Institute, Detroit (1991).

13. Newmark, N. M. and Hall, W. J., "Earthquake spectra and design," Earthquake Engineering Research Institute, El Cerrito, California (1982). 